\title{
KAKO DRUGAČE REČI »JAZ«: PRISOTNOST KNJIG V DELIH PRIMA LEVIJA
}

Ključne besede: italijanska književnost, Primo Levi, knjige, branje, avtobiografija, antologija

\section{Uvod}

Literarna produkcija Prima Levija je izjemno raznolika in se nikakor ne zvede na avtobiografijo, čeprav je avtor najširše preučevan predvsem zaradi svojih avtobiografskih del. Vendar pa je prav v besedilih, ki se v različnih oblikah navezujejo na avtobiografijo, najbolj opazna močna in stalna prisotnost knjig, ki jo analizira pričujoči prispevek.

Začetki Levijevega pisanja so odločilno povezani z avtobiografskimi vzgibi. Avtor, ki se opredeljuje kot »kemik, ki ob nedeljah - in niti ne ob vseh - postane pisatelj« (Levi, 2003, 135), namreč začne pisati prav zaradi temeljne potrebe po izpovedi svojega ujetništva v Auschwitzu, ki jo udejanji v avtobiografskih romanih Ali je to človek (Se questo è un uomo, 1947 in 1958) ter Premirje (La tregua, 1963). ${ }^{1}$ Kot poudarja sam Levi, »če ne bi doživel Auschwitza, verjetno ne bi nikoli ničesar napisal. Ne bi imel motiva, spodbude za pisanje [...] V pisanje me je prisilila prav moja izkušnja taborišča« (Levi, 1989, 349). ${ }^{2}$ Avtobiografskima romanoma se pozneje pridružijo avtobiografske kratke zgodbe, ki poleg tematike koncentracijskih taborišč

1 Slovenski prevod obeh del (S. Šlenc) je izšel leta 2004.

2 Vsi prevodi iz italijanskih besedil, ki še niso prevedena v slovenščino: I. Prosenc Šegula. 
obravnavajo tudi druga obdobja Levijevega življenja in so zbrane predvsem v Periodnem sistemu (Il sistema periodico, 1975). ${ }^{3}$

Poleg avtobiografije Levijeva produkcija obsega povsem različne zvrsti, od romanov ${ }^{4}$ in poezije ${ }^{5}$ do fantastičnih in znanstvenofantastičnih kratkih zgodb $^{6}$ ter esejističnih besedil. ${ }^{7}$ Vendar pa avtor komentira, da je v delu njegove produkcije močno zastopana »odkrita ali prikrita avtobiografija» (Levi, Intervista, 1994, 248; prim. tudi Levi, 1998, 159). Ta navezava na avtobiografijo je opazna zlasti v esejističnih besedilih, ki se nemalokrat vračajo k avtobiografskim motivom ali celo pretežno izhajajo iz njih, kot na primer Potopljeni in rešeni (I sommersi e i salvati, 1986), ${ }^{8}$ eno Levijevih zadnjih del. Esejistična besedila pogosto odsevajo še eno temeljno značilnost Levijevega dela, ki jo učinkovito povzema ugotovitev C. Segreja, da »kritik pri Leviju ne more dosti zgrešiti, saj se je odlično pojasnil že sam « (Segre, 1988, VIII). Gre za izrazito metaliterarno naravnanost, ki se izraža v člankih, spremnih in uvodnih besedah ter intervjujih, $\mathrm{v}$ katerih Levi komentira in razčlenjuje svoja literarna dela, vzgibe za pisanje, postopke pisanja, genezo svojih del, njihovo prevajanje in recepcijo, pa tudi svoje odzive na recepcijo.

Levi se torej po eni strani analizira kot avtor, po drugi pa kot človek, ki je preživel skrajno izkušnjo, pri čemer sta metaliterarno razmišljanje in avtobiografska pripoved pogosto tesno povezani. Levi namreč avtobiografske prvine povezuje z značilnostmi svojih književnih besedil in hkrati začrtuje nekakšno avtobiografijo samega sebe kot avtorja. Tako tudi tu udejanja vodilo "prepoznati, analizirati in stehtati« (Levi, 2003, 114), ki ga eksplicitno izvaja iz svojega poklica: »[K]emija je umetnost ločevanja, tehtanja in razlikovanja, ta tri opravila pa so koristna tudi za tistega, ki se loti opisovanja dejstev ali udejanjanja lastne domišljije« (Levi, 1998, 13).

3 Slovenski prevod (M. Cenda-Klinc) je iz leta 1992. Nekaj avtobiografskih kratkih zgodb je objavljenih tudi v zbirki Lilít (1981) in posthumni zbirki L’ultimo Natale di guerra (2000).

La chiave a stella (1978), Se non ora, quando? (1982).

5 Ad ora incerta (1984), slovenski prevod Ob negotovi uri (J. Milič) je iz leta 2007.

6 Te so zbrane v zbirkah Storie naturali (1966), Vizio di forma (1971) ter že omenjenih Lilít in Lultimo Natale di guerra.

7 V zbirki L’altrui mestiere (1985) so izšla esejistična besedila, objavljena med letoma 1964 in 1984, v posthumni izdaji L’asimmetria e la vita. Articoli e saggi 1955-1987 (2002) pa besedila iz obdobja od 1955 do avtorjeve smrti.

8 Slovenski prevod (I. Prosenc Šegula) je izšel l. 2003. 
Pisanje kot »orodje, namenjeno tehtanju, ločevanju, preverjanju« (Levi, 2002, 147), pa Levi posveti še enemu vidiku analize, to je razmišljanju o književnih delih drugih avtorjev. Tudi tu stopa v ospredje samoanaliza, saj so tuja literarna dela avtorju pogosto iztočnica za razmišljanje o sebi kot o bral$\mathrm{cu}$, torej za še eno obliko samorefleksije. Levi je kot bralec, ki analizira samega sebe, po eni strani nosilec abstraktnega znanja in pojmov, izhajajočih iz preteklih branj, po drugi strani pa lastnik knjig kot konkretnih predmetov, ki so bodisi razporejeni v določenem redu na njegovih knjižnih policah bodisi spremljevalci v bolj ali manj kočljivih obdobjih njegovega življenja bodisi omembe vreden del prtljage na njegovih poteh skozi vojno in povojno Evropo. Knjige se v različnih oblikah pojavljajo zlasti v avtobiografskih in esejističnih besedilih, katerih prvine se, kot smo že nakazali, pogosto prepletajo, zato se pričujoči prispevek posveča prav temu delu Levijeve produkcije.

\section{Avtor kot bralec}

Levi se na podobo samega sebe kot bralca najbolj osredotoča v delu Iskanje korenin: osebna antologija (La ricerca delle radici: antologia personale, 1981), v katerem se prepletajo obravnave knjige kot konkretnega predmeta, književnega dela in kot pojma, prežetega $\mathrm{z}$ avtobiografskimi prvinami. Zasnova dela je edinstvena; ne gre namreč za antologijo Levijevih lastnih besedil, temveč za nekakšen »avtoportret [...], sestavljen iz besed drugih « (Belpoliti, 1997, VII; prim. tudi Belpoliti, 1998, 130), torej za antologijo besedil drugih avtorjev. Pobudo za tovrstno delo je dal eden vodilnih italijanskih urednikov 20. stoletja Giulio Bollati, ki je leta 1980 nekaterim pisateljem predlagal, naj sestavijo antologijo besedil, ki so najbolj vplivala nanje, vendar se je s konkretnim izborom odzval samo Levi ${ }^{9}$ (prim. Belpoliti, 1997, VII-VIII; Belpoliti, 1998, 131; Andreoli, 1997, 123; Calvino, 1997, 239).

Pri svojem izboru besedil Levi izhaja iz vprašanja: "Koliko naših korenin izhaja iz knjig, ki smo jih prebrali? Vse, veliko, malo ali nič, odvisno od

9 Šele pozneje je podobno antologijo sestavil P. V. Mengaldo (Antologia personale, 1995), prav tako na Bollatijev predlog. 
okolja, v katerem smo se rodili, od temperature naše krvi, od blodnjaka, ki nam ga je dodelila usoda (Levi, 1997, XIX). Podobno kot v mnogih drugih kontekstih, kjer razčlenjuje svojo osebno in pisateljsko identiteto, se tudi pri antološkem izboru naveže na njemu ljubo prispodobo hibridnosti, dvojnosti, s katero opredeli raznoliko naravo izbranih besedil. Izhaja iz hipoteze, da lahko razmišljanje o lastnih čtivih razkrije intertekstualno vpetost besedil v širši literarni kontekst:

Ker je moj input hibriden, sem $\mathrm{z}$ veseljem in radovednostjo sprejel predlog, naj tudi jaz sestavim »osebno antologijo « [...] v smislu [...] v dobri veri sestavljene retrospektivne zbirke, ki naj bi osvetlila morebitne sledove tega, kar je bilo prebrano, v tem, kar je bilo napisano. (Levi, 1997, XIX)

Toda ob razčlenjevanju svojih prepletenih identitet bralca in avtorja naposled sklene, da med njima ni neposredne povezave: »Bral sem precej, vendar mislim, da me stvari, ki sem jih prebral, ne uokvirjajo; verjetno se v mojem pisanju dosti bolj pozna to, da sem trideset let opravljal tehnični poklic, kot pa knjige, ki sem jih prebral« (Levi, 1997, XIX), in poudari: "Morda se prebrane stvari tu in tam pokažejo na straneh, ki sem jih pozneje napisal, vendar srž mojega pisanja ni v tem, kar sem prebral« (Levi, 1997, $\mathrm{XX})$. V Levijevi »osebni antologiji« torej ne gre nujno za iskanje književnih vplivov na lastno delo, kar avtor eksplicira tudi v intervjuju, v katerem pojasnjuje postopek izbiranja antoloških besedil in poudari njegovo avtobiografsko naravo:

Tovrstna izbira je avtobiografsko delo. Vendar to še nisem ves jaz. Nisem se rodil kot pisatelj, moje »korenine« so le delno književne, trideset let sem s polnim delovnim časom opravljal poklic kemika, ki me je včasih navduševal, včasih tiral v obup, to je bilo pač življenje znotraj življenja. [...] Knjigo bi si bil želel nasloviti: »Kako drugače reči jaz«. (Andreoli, 1997, 123-124) ${ }^{10}$

Kot opozarja Mengaldo, v Levijevi antologiji prav tako ne gre za raziskovanje etnične identitete, četudi bi nemara »od preganjanega Juda pri-

10 »Kako drugače reči jaz« se je v Iskanju korenin ohranil kot naslov, ki ga je Levi dal odlomku iz Jakobovih zgodb Thomasa Manna. 
čakovali, da bo iskal lastne etnične korenine« (Mengaldo, 1989, 94). Levi med besedila sicer vključi tudi judovske avtorje, vendar zgolj na podlagi »daljnega judovskega sorodstva" (Levi, 1997, XXII), in jih ne uvrsti med dela, ki so mu najbližja.

$\mathrm{V}$ antologiji je nanizanih trideset raznolikih besedil in avtorjev, med katerimi je na prvem mestu biblijska Jobova knjiga, ${ }^{11}$ sledijo pa ji dela Homerja, Darwina, Conrada, Rabelaisa, Marca Pola, Lukreca ter Brownova in Clarkova znanstvenofantastična besedila, Langbeinove študije o Auschwitzu, poljudnoznanstvena besedila in Gattermannov strokovni kemijski priročnik. V kratkih uvodih, ki spremljajo vsako od besedil, Levi pojasni, kakšen pomen imajo v njegovem življenju, v predgovoru pa opredeli splošne kriterije izbire, ki so pogosto avtobiografski.

O merilih, zaradi katerih so določena dela bralcu ljuba, sicer razmišlja tudi na drugih mestih:

Nekatere knjige so nam ljube, ne da bi mogli pojasniti zakaj; če bi te primere zadosti poglobljeno raziskali, bi verjetno ugotovili neslutene sorodnosti, ki bi nam veliko razkrile o manj vidnih plateh našega značaja. Druge knjige pa nas spremljajo leta in leta, vse življenje in razlog za to nam je jasen, dosegljiv ter ga zlahka izrazimo z besedami. (Levi, 1998, 15)

V Iskanju korenin Levi nekaj besedil označi kot svoje "najgloblje in najdlje trajajoče ljubezni«, ki pa so hkrati tudi »najmanj utemeljene«, druga izbere zaradi "poklicne bližine«, »skupne ljubezni do potovanj in pustolovščin «, že omenjenega »daljnega judovskega sorodstva«, ki ga sopostavi »bližnjemu sorodstvu « z nekaterimi drugimi avtorji, pa tudi »osebnega prijateljstva (Levi, 1997, XXII). Še posebej izpostavi avtobiografske razloge, zaradi katerih je v antologijo uvrstil roman Rogerja Vercela Remorques: prebral ga je namreč 18. januarja 1945 v Auschwitzu, medtem ko je hudo bolan ležal v bolniškem bloku in čakal, ali bodo Nemci pobili jetnike ali zbežali pred napredujočo Rdečo armado. Po enem letu taborišča, ko je »poleg lakote ob pomanjkanju kruha trpel tudi zaradi lakote ob pomanjkanju

11 Vodilno mesto $\mathrm{v}$ antologiji in pomen Jobovega lika v Levijevem delu obravnavata NezriDufour $(2002,191-195$ in 214-220), ter Scarpa $(1997,244)$. 
pisane besede«, je bil Vercelov roman prva knjiga, ki je je bil deležen po »dolgem postu« (Levi, 1997, 111). Kot v Iskanju korenin opozarja sam, o knjigi (ne da bi omenil njen naslov) pripoveduje tudi v zadnjem poglavju romana Ali je to človek, ko mu knjiga pride v roke v enem najbolj kočljivih trenutkov jetništva v Auschwitzu:

Pozno ponoči je spet prišel grški zdravnik $\mathrm{z}$ volneno oglavnico in nahrbtnikom. Na moj pograd je zalučal francoski roman: »Na, Italijan, beri! Vrneš mi, ko se spet vidiva.« Še danes ga zaradi teh besed sovražim: vedel je, da smo obsojeni. [...] Popoldan sem prebil ob branju knjige, ki mi jo je pustil zdravnik: bila je zelo zanimiva in se je nenavadno točno spominjam. [...] Kmalu se je spustila noč in električna žarnica je še brlela. Z mirnim strahom smo opazili, da na vogalu barake stoji oborožen esesovec. Ni mi bilo do pogovora in ni me bilo strah. Pravzaprav, bal sem se [...] le na zunanji, pogojni način. Bral sem pozno v noč. (Levi, 2004, 138-139)

Knjiga tako v avtobiografskem kontekstu postane pomemben del dogajanja, o katerem želi avtor pričevati. Zlasti v povezavi s taboriščno tematiko sta namreč za Levija osrednjega pomena spomin in pričevanje. Branje, pa tudi knjiga kot predmet, sta tako po eni strani vredna obeleženja in pričevanja, po drugi strani pa privzameta vlogo spominskega pripomočka, ki pripovedovalcu pomaga priklicati $\mathrm{v}$ spomin okolje in dogodke, $\mathrm{v}$ katerih sta se pojavila.

\section{Bralne navade}

Levi tako $\mathrm{v}$ Iskanju korenin kot $\mathrm{v}$ drugih besedilih rad pripoveduje o svojih bralnih navadah. Za svoj odnos do knjig, ki jih je »neprenehoma hlastno požiral « (Levi, Periodni, 1992, 25), pravi, da se ga je navzel od družine, posebej od očeta, ki je bral vse po vrsti, imel žepe »vedno nabasane s knjigami« (Levi, Periodni, 1992, 22) in »kot strokovnjak zahajal na vse stojnice [...], kjer so se prodajale rabljene knjige« (Levi, 1998, 186):

Veliko sem bral, saj sem pripadal družini, v kateri je bilo branje nedolžna in tradicionalna razvada, hvaležna navada, umska gimnastika, obvezen in prisilen 
način mašenja časovnih lukenj ter nekakšna fatamorgana modrosti. Moj oče je vedno bral po tri knjige hkrati; bral je, »ko je bival v svoji hiši in ko je hodil po poti, ko je legal in ko je vstajal« $(\mathrm{Mz} 6,7)$; krojaču je dajal šivati suknjiče s širokimi in globokimi žepi, da je lahko nosil v vsakem po eno knjigo. Imel je brata, ki sta prav tako hlastno brala vse povprek; vsi trije (eden inženir, drugi zdravnik, tretji borzni posrednik) so se imeli zelo radi, vendar so drug drugemu kradli knjige iz knjižnic ob vseh mogočih priložnostih. Okradenci so se sicer pritoževali, a le zaradi lepšega, $\mathrm{v}$ resnici pa so se $\mathrm{v}$ športnem duhu sprijaznili s krajo, kot če bi obstajalo nekakšno nenapisano pravilo, po katerem je človek, ki si resnično želi neko knjigo, ipso facto tudi vreden, da jo odnese in si jo prilasti. Zato sem mladost preživel v okolju, nasičenem s pisano besedo, v katerem so bili šolski učbeniki v manjšini; tudi sam sem po domačem običaju bral zmedeno, nemetodično in sem verjetno spričo tega pridobil določeno (pretirano) zaupanje $\mathrm{v}$ plemenitost in nujnost pisane besede. (Levi, 1997, XX)

Poleg svojih bralnih navad Levi obravnava tudi svoje ravnanje s knjigami kot predmeti, ki ga poveže z izbiro antoloških besedil za Iskanje korenin:

Tako pri posamičnih besedilih in avtorjih kot pri odlomkih iz dela vsakega avtorja je bila moja izbira iskrena in skorajda samodejna. Imam navado, da postavljam vse svoje najljubše knjige, neodvisno od teme in starosti, na isto polico, in vse so obilno podčrtane na mestih, ki jih rad znova prebiram, zato nisem imel veliko dela. (Levi, 1997, XXIII)

V članku o Aldousu Huxleyju (Levi, 1998, 8-11) se avtor prek knjige kot predmeta, ki mu je namenjeno določeno mesto na polici, spet navezuje na svoje bralne navade, med katere uvrsti tudi nagnjenost $\mathrm{k}$ ponovnemu branju (prim. tudi Levi, 1998, 74):

Polica, na kateri imam knjige Aldousa Huxleyja, je zame stalna skušnjava: skušnjava, da zaprem knjigo, ki jo berem, ter ponovno vzamem v roke in naključno odprem eno njegovih del. To, da opustim knjigo, ki je še nisem prebral do konca, in začnem brati drugo, je graje vredno in tega se povsem zavedam. Nepošteno je, kot majhna izdaja: ne veš, kaj ti je avtor prihranil na naslednji strani, ki je še nisi prebral, nočeš mu slediti in ga poslušati, slab sodnik si, ki utiša pričo, še preden je končala s pričanjem; toda skušnjava je velika in pri tem me spodbuja zgled samega Huxleyja, ki je priznaval, da je »desultory reading «, branje brez reda, njegova najljubša razvada. (Levi, 1998, 8) 


\section{Branje kot del avtobiografije}

V Levijevih avtobiografskih besedilih so knjige umeščene v pripoved o raznih obdobjih avtorjevega življenja, pri tem pa jim je namenjena enaka pozornost kot preostalim predmetom, okolju, ljudem in dogodkom. Avtor omenja njihove naslove, včasih opiše njihovo zunanjo podobo, pripoveduje, kako je prišel do njih in kako jih je izgubil ter kaj in kje je bral. Občasno poda tudi mnenje o prebranih delih, vendar je to $\mathrm{v}$ avtobiografskih besedilih (v nasprotju z esejističnimi) redkejše in manj poudarjeno kot okoliščine branja in samo branje. Knjiga je, denimo, v ospredju pri poskusu zbližanja s sošolko na fakulteti:

Ko sem tako brenčal okrog Rite, sem se zavedel še druge srečne okoliščine: iz dekletove torbice je štrlela znana platnica, rumenkasta $\mathrm{z}$ rdečim robom, na njej je bil narisan krokar s knjigo v kljunu. Naslov? Razbrati je bilo mogoče le "OBNA« in »ORA«, toda zadostovalo je: bila je moja dušna popotnica v tistih mesecih, zgodba za vse čase, ki govori o Johannu Castorpu v magičnem izgnanstvu na čarobni gori. Rito sem povprašal, kakšno je njeno mnenje o knjigi, zaskrbljen, kot da bi jo bil jaz napisal; tako sem ugotovil, da je knjigo sprejemala popolnoma drugače kot jaz. Brala jo je kot roman in nič več kot to: zanimalo jo je, do kod se bo Johann spustil z gospo Chauchat, in je neusmiljeno izpuščala (zame) očarljive razprave humanista Settembrinija $\mathrm{z}$ židovskim jezuitom Naphto o politiki, teologiji in metafiziki. (Levi, Periodni, 1992, 35)

Ko Levija pozneje kljub rasnim zakonom, ki prepovedujejo zaposlovanje Judov, zaposlijo v odročnem rudniku, v pripovedovanje o svojem tamkajšnjem življenju vključi branje in navede naslov dela, ki ga je bral; znova gre za enega njegovih najljubših avtorjev, Thomasa Manna, ki ga vključi tudi v Iskanje korenin: »Druge krati sem se zapiral v svojo meniško sobico v Podmornici, da sem bral zgodbe o Jakobu «12 (Levi, Periodni, 1992, 67). Ob odhodu iz rudnika med svojo najpomembnejšo lastnino poudari prav

12 Mannov roman, ki ima $\mathrm{v}$ obstoječem slovenskem prevodu naslov Jakobove zgodbe, Levi $\mathrm{v}$ italijanskem izvirniku Periodnega sistema navede z veliko začetnico: »mi chiudevo a leggere le Storie di Giacobbe nella mia cameretta monastica del Sottomarino« (Levi, 1994, 77). Kot je razvidno iz citata, pa je v slovenskem prevodu Periodnega sistema (M. Cenda-Klinc) uporabljena nekoliko drugačna oblika naslova, in to $\mathrm{z}$ malo začetnico. 
knjige: "S seboj sem vzel samo tiste stvari, ki sem jih nujno potreboval: bicikel, Rabelaisa, Macaroneae, Moby Dick v Pavesejevem prevodu in še nekaj drugih knjig, cepin, plezalno vrv, logaritemsko računalo in kljunasto flavto« (Levi, Periodni, 1992, 95).

Močna navzočnost knjig $\mathrm{v}$ pripovedi, navajanje njihovih naslovov in spominjanje preteklih branj nakazujejo, da avtor s pozornostjo in užitkom razmišlja o sebi kot o bralcu. Hkrati se po ujetništvu v koncentracijskem taborišču prav s pomočjo branja vrača $\mathrm{v}$ civilizacijo in znova privzema identiteto, ki bi morala biti po taboriščnih zapovedih izničena; na primer $\mathrm{v}$ Premirju, ko po osvoboditvi Auschwitza okreva po hudi bolezni:

Še kakih dvajset dni nisem šel iz sobe. Neskončno dolge dneve sem preživljal leže in hlastno prebiral tistih nekaj knjig, ki sem jih utegnil ukrasti: veliko angleško slovnico v poljščini, Marie Walewska, le tendre amour de Napoléon, priročnik osnovne trigonometrije, Maščevanje Rouletabilla, Cayenski kaznjenci ter čuden roman nacistične propagande, Die Grosse Heimkehr (Velika vrnitev), ki je opisoval tragično usodo čiste nemške rase v vasi nekje v Galiciji, ki jo mučijo, ropajo in slednjič požgejo surovi Poljaki pod vodstvom maršala Becka. (Levi, 2004, 227)

Eklektični seznam čtiv se povezuje z že omenjenimi Levijevimi komentarji glede bralnih navad, ki jih je podedoval po svoji družini. Na te navade se naveže tudi, ko pripoveduje, kako je bral priročnik o porodništvu, pri čemer v pripoved znova vključi okoliščine, v katerih je prišel do knjige, in opis same knjige: »Na nekem podstrešju sem našel nemško razpravo o porodništvu v dveh zvezkih z lepimi ilustracijami, in ker je pisana beseda moja razvada, ki se ji nisem mogel vdajati več kot leto dni, sem preživljal ure v naključnem branju« (Levi, 2004, 254). V povezavi s porodniškim priročnikom se znova izkaže, da Levi poudarja knjige, svoje »dušne popotnice«, kot omembe vreden del lastnine v težkih življenjskih obdobjih. Po odhodu iz Auschwitza, s katerim se za preživele začne negotova pot po povojni Evropi, namreč Levi zvezka vključi med svojo prtljago, v kateri predstavljata »zdaleč najtežji del«, in pove tudi, kako je bil naposled obnju (Levi, 2004, 255). Ker po drugi strani pripovedovalec ne omeni, kaj drugega naj bi še sestavljalo borno prtljago, lahko sklepamo, da sta bili knjigi ne le njen najtežji, temveč v pripovedovalčevih očeh tudi najpomembnejši del. 
Pomen, ki ga ima za Levija pisana beseda, je najbolj razviden v delu Ali je to človek. Čeprav so knjige v Auschwitzu strogo prepovedane in torej $\mathrm{v}$ letu Levijevega ujetništva popolnoma odsotne, avtor celotno poglavje nameni Dantejevi Božanski komediji: »... Odisejev spev. Kdove zakaj in kako mi je padel na um [...] ... Kdo je Dante. Kaj je Božanska komedija. Kakšen čuden občutek novosti zaznavaš, če skušaš na kratko pojasniti, kaj je to Božanska komedija, kako je razdeljen Pekel, kaj je to zakon povrnitve« (Levi, 2004, 99).

Simbolični pomen Božanske komedije kot jamstva kulture in civilizacije ter intertekstualna razmerja med Levijevim avtobiografskim romanom in Božansko komedijo so preučili številni kritiki (prim. Segre, 1996; Mondo, 1995; Belpoliti, 1998, 60-65; Cases, 1987, XVIII-XIX; Boitani, 1992, 183188). Čeprav je prav Dante eden od avtorjev, ki jih Levi v Iskanje korenin ni vključil - s pojasnilom, da je kot klasik pač del sleherne knjižnice (Andreoli, 1997, 125) -, je Božanska komedija eden od temeljev njegove kulturne identitete. Na drugem polu Levijeve hibridne identitete najdemo povsem drugačno vrsto besedil, in sicer strokovne, predvsem kemijske tekste (prim. Cases, 1990), ki pa so v njegovi pripovedi enakovredni književnim besedilom. Najpogostejši so v Periodnem sistemu, saj se v njem avtobiografija prepleta s kemijsko izobrazbo in poklicem: učbenik avtorjev Sestinija in Funara (Levi, Periodni, 1992, 28), Autenriethov učbenik (Levi, Periodni, 1992, 38), pa tudi obskurna Kerrnova razprava o diabetesu (Levi, Periodni, 1992, 99-100; 102-103), ki je po avtorjevih besedah »čudna knjiga: težko bi jo bili napisali in natisnili kje drugje kot v tretjem rajhu « (Levi, Periodni, 1992, 102).

Najpomembnejše mesto med priročniki ima že omenjeni Gattermannov kemijski učbenik, ki ga Levi v poglavju »Očetove besede« vključi v Iskanje korenin. Tako kot prej omenjeni priročniki se Gattermannov učbenik pojavi v Periodnem sistemu (Levi, Periodni, 1992, 49), predvsem pa v romanu Ali je to človek (Levi, 2004, 94), kjer kot kemik - Jud v koncentracijskem taborišču - dela izpit pri esesovskem kemiku:

Izpit gre dobro. Ko se sproti tega zavem, se mi zdi, da tudi sam rasem. Zdaj me sprašuje, o čem sem napisal diplomsko nalogo. Moram se z vso silo potruditi, 
zbuditi v sebi zaporedje tako daljnih spominov, kot bi se skušal spomniti dogodkov neke prejšnje inkarnacije.

A nekaj me varuje. Moje uboge stare Mere dielektričnih konstant še posebej zanimajo tega plavolasega arijca, ki mu je eksistenca zagotovljena: vpraša me, če znam angleško, in mi kaže Gattermannov učbenik in tudi to je absurdno in neverjetno, da tu, onstran bodeče žice, obstaja nek Gattermann, ki je prav takšen, kot je bil tisti, iz katerega sem se učil v četrtem letniku, doma v Italiji. (Levi, 2004, 94)

Ne le klasiki italijanske književnosti, temveč tudi kemijski priročnik je torej povezava s prejšnjim, običajnim, človeka vrednim življenjem, ki nasprotuje razčlovečenju koncentracijskega taborišča.

\section{Zaključek}

K svojim eklektičnim bralnim navadam se Levi vrne v eseju "Fosilne besede« - »Le parole fossili« (Levi, 1998, 206-210), v katerem poudarja svoje raznolike interese, pa tudi nagnjenost $\mathrm{k}$ spontanemu, nerednemu branju:

Če je sploh še potrebno, moram priznati, da tu govorim o svoji stari šibki točki, se pravi o tem, da se v prostih uricah ukvarjam s stvarmi, ki jih ne razumem, pa ne zato, da bi si zgradil celovito kulturo, temveč zgolj za zabavo, iz čistega ljubiteljskega užitka. Raje prisluškujem, kot poslušam, oprezam skozi ključavnice, kot opazujem širne in svečane panorame; raje sučem med prsti en sam kamenček, kot pa da bi občudoval celotni mozaik. Zato se mi moji družinski člani dobrodušno smejijo, kadar vidijo (in to se pogosto pripeti), da držim v roki slovar ali glosar namesto romana ali razprave; res je, raje imam posamično od splošnega, raje neredno in razdrobljeno kot pa sistematično branje. (Levi, 1998, 207)

Levi nam $\mathrm{v}$ tem komentarju potrdi podobo samega sebe kot bralca. Gradi jo zlasti v povezavi z avtobiografsko pripovedjo. Ta podoba po eni strani odseva »hibridnost « in pestrost njegovih interesov, ki so očitni tudi $\mathrm{v}$ raznolikosti njegove literarne produkcije, po drugi strani pa prek podedovanih navad vzdržuje vez $\mathrm{z}$ družino in tako utrjuje njegove korenine. Knjige kot predmeti, branje in književni spomini imajo v Levijevi avtobio- 
grafski pripovedi in esejističnih besedilih pomembno mesto, saj jih avtor s pozornostjo in natančnostjo vključuje $\mathrm{v}$ pripoved. Njihove korenine segajo globoko in zlasti v koncentracijskem taborišču kljub nacistični politiki razčlovečenja protagonista umeščajo $\mathrm{v}$ civilizacijo in kulturo ter mu pomagajo vzdrževati njegovo človeško identiteto.

\section{LITERATURA}

Andreoli, A., Per Primo Levi questo è un mondo diverso di dire io, v: Levi, P., Conversazioni e interviste 1963-1987 (ur. Belpoliti, M.), Torino, 1997, 123-128.

Belpoliti, M., Le radici rovesciate, v: Levi, P., La ricerca delle radici, Torino, 1997, VII-XVIII.

Belpoliti, M., Primo Levi, Milano, 1998.

Boitani, P., Lombra di Ulisse. Figure di un mito, Bologna, 1992.

Calvino, I., Le quattro strade di Primo Levi, v: Levi, P., La ricerca delle radici, Torino, 1997, 237-241.

Cases, C., Introduzione. L'ordine delle cose e l'ordine delle parole, v: Levi, P., Opere, I, Torino, 1987, IX-XXXI.

Cases, C., Sodio e potassio: scienza e visione del mondo in Primo Levi, v: Primo Levi as Witness: Proceedings of a Symposium held at Princeton University, April 30 - May 2, 1989 (ur. Frassica, P.), Firenze, 1990, 21-30.

Levi, P., Ad ora incerta, Milano, 1984.

Levi, P., Ali je to človek / Premirje (prev. Šlenc, S.), Ljubljana, 2004.

Levi, P., Appendice a 'Se questo è un uomo', v: Se questo è un uomo. La tregua, Torino, 1989, 327-350.

Levi, P., Il sistema periodico, Torino, 1994.

Levi, P., I sommersi e i salvati, Torino, 1991.

Levi, P., La chiave a stella, Torino, 1991.

Levi, P., Laltrui mestiere, Torino, 1998.

Levi, P., La ricerca delle radici, Torino, 1997.

Levi, P., L'asimmetria e la vita, articoli e saggi 1955-1987 (ur. Belpoliti, M.), Torino, 2002. 
Levi, P., Ob negotovi uri (prev. Milič, J.), Ljubljana, 2007.

Levi, P., Periodni sistem (prev. Cenda-Klinc, M.), Maribor, 1992.

Levi, P., Potopljeni in rešeni (prev. Prosenc Šegula, I.), Ljubljana, 2003.

Levi, P., Se non ora, quando?, Torino, 1992.

Levi, P., Se questo è un uomo. La tregua, Torino, 1989.

Mengaldo, P. V., Ciò che dobbiamo a Primo Levi, v: Tre narratori. Calvino, Primo Levi, Parise (ur. Folena, G.), Padova, 1989, 89-98.

Mondo, L., Primo Levi e Dante, v: Primo Levi: memoria e invenzione, Atti del convegno internazionale, San Salvatore Monferrato, 26-27-28 settembre 1991 (ur. Ioli, G.), San Salvatore Monferrato, 1995, 224-229.

Nezri-Dufour, S., Primo Levi: una memoria ebraica del Novecento, Firenze, 2002.

Scarpa, D., Chiaro/oscuro, v: Primo Levi (ur. Belpoliti, M.), Milano, 1997, 230-253.

Segre, C., Se questo è un uomo di Primo Levi, v: Letteratura italiana, Le Opere, IV, Il Novecento, II. La ricerca letteraria (ur. Asor Rosa, A.), Torino, 1996, 491-508. 


\section{A DIFFERENT WAY OF SAYING "I": THE PRESENCE OF BOOKS IN PRIMO LEVI'S WORKS}

Keywords: Italian literature, Primo Levi, books, reading, autobiography, anthology

\section{Abstract}

Primo Levi's literary production is extremely varied and cannot be limited to autobiography despite the fact that the author is primarily studied for his autobiographical works. However, his texts related to autobiography show the strongest and most consistent presence of books, which is analyzed in this article.

The beginnings of Levi's writing can be traced to autobiographical motifs. Autobiography, which is present in a considerable part of the author's work, is particularly connected to essays that often include autobiographical elements. Levi analyzes himself as an author as well as a reader, thus putting into practice the motto of "recognizing, analyzing, and weighing," derived from his profession as a chemist. As a self-analyzing reader, he is a carrier of abstract notions deriving from previous readings as well as the owner of books intended as concrete objects displayed on his bookshelves. Books are his "soul companions" over various periods of his life and a conspicuous part of luggage on his wanderings through postwar Europe.

The clearest image of Levi as a reader is found in The Search for Roots: A Personal Anthology. Levi's selection of thirty texts by other authors combines depictions of books as concrete objects, literary works, and notions permeated with autobiographical elements. The choice of excerpts, varying from literary to scientific texts, is based mostly on autobiographical motifs.

In Levi's autobiographical texts, books and reading assume an important role in reminiscing and testifying about past events. The author also elaborates on his eclectic reading habits, inherited from his family, as well as on the way he handles books as objects. In his autobiographi- 
cal narrative, books are given the same attention as other objects, people, and places, often including their titles, a physical description, the circumstances in which the author came into their possession, and the places where he read them. After Levi's annihilating experience of imprisonment in Auschwitz, reading is also a means of returning to civilization and reacquiring the identity that the concentration camp had every intention of destroying. Levi's "hybrid" cultural identity includes classics of Italian literature as well as chemistry textbooks, which are both important in creating the roots of the author's identity within his family as well as within human civilization. 